\title{
Molecular testing for adult type Alport syndrome
}

Genevieve Pont-Kingdon*1, Kelli Sumner ${ }^{1}$, Friederike Gedge ${ }^{1}$, Chris Miller ${ }^{2}$, Joyce Denison ${ }^{3}$, Martin Gregory ${ }^{3}$ and Elaine Lyon ${ }^{2,3}$

\author{
Address: ${ }^{1}$ ARUP institute for Clinical and Experimental Pathology, Salt Lake City, UT, USA, ${ }^{2}$ ARUP Laboratories, Salt Lake City, UT, USA and \\ ${ }^{3}$ University of Utah, School of Medicine, Salt Lake City, UT, USA \\ Email: Genevieve Pont-Kingdon* - pontkig@aruplab.com; Kelli Sumner - kelli.sumner@aruplab.com; \\ Friederike Gedge - Friederike.gedge@aruplab.com; Chris Miller - MILLERC@aruplab.com; Joyce Denison - koyce.denison@m.cc.utah.edu; \\ Martin Gregory - martin.gregory@hsc.utah.edu; Elaine Lyon - lyone@aruplab.com \\ * Corresponding author
}

Published: 17 November 2009

BMC Nephrology 2009, 10:38 doi:10.1 186//47/-2369-10-38

This article is available from: http://www.biomedcentral.com//47/-2369//0/38

(C) 2009 Pont-Kingdon et al; licensee BioMed Central Ltd.

This is an Open Access article distributed under the terms of the Creative Commons Attribution License (http://creativecommons.org/licenses/by/2.0), which permits unrestricted use, distribution, and reproduction in any medium, provided the original work is properly cited.
Received: 14 May 2009
Accepted: 17 November 2009

\begin{abstract}
Background: Alport syndrome (AS) is a progressive renal disease with cochlear and ocular involvement. The majority of AS cases are X-linked (XLAS) and due to mutations in the COL4A5 gene. Although the disease may appear early in life and progress to end stage renal disease (ESRD) in young adults, in other families ESRD occurs in middle age. Few of the more than four hundred mutations described in COL4A5 are associated with adult type XLAS, but the families may be very large.
\end{abstract}

Methods: We classified adult type AS mutation by prevalence in the US and we developed a molecular assay using a set of hybridization probes that identify the three most common adult type XLAS mutations; CI564S, LI649R, and RI677Q.

Results: The test was validated on samples previously determined to contain one or none of these mutations. In the US, the test's clinical specificity and sensitivity are estimated to be higher than $99 \%$ and $75 \%$ respectively. Analytical specificity and sensitivity are above $99 \%$.

Conclusion: This test may be useful for presymptomatic and carrier testing in families with one of the mutations and in the diagnosis of unexplained hematuria or chronic kidney disease.

\section{Background}

Alport syndrome (AS) is a progressive inherited disease characterized by persistent hematuria that progresses to ESRD. The disease is often accompanied by progressive hearing loss and ocular lesions. AS is due to defects in type IV collagen alpha chain 3, 4 or 5 encoded respectively by the COL4A3, COL4A4 and COL4A5 genes. The majority $(>80 \%)$ of AS is X-linked with mutations found in the COL4A5 gene [1]. Autosomal recessive and dominant forms also exist due to mutations in COL4A3 or COL4A4.
More than 400 mutations causing XLAS have been described in COL4A5 http://www.arup.utah.edu/data base/ALPORT/ALPORT welcome.php. Genotype-phenotype correlations have been established by several groups [2-4]. Large rearrangements, nonsense and frameshift mutations cause juvenile onset disease in most patients. Other mutations such as some splice variants and glycine substitutions in the GXY collagen repeats, specifically in exons 1-20, confer later onset disease [2]. Amino acid substitutions in the $\mathrm{N}$ non-collagenous (NC1) domain of the 
alpha 5 chain were described in families with adult onset (ESRD at $>30$ years old) XLAS with or without hearing loss [5-7].

Among mutations for adult type AS, L1649R was discovered in 9 kindreds and traced to a single common ancestor in New England more than 200 years ago [6]. C1564S was discovered in one very large kindred residing in the US [1]. R1677Q was found in three families of Ashkenazi Jewish descent [5]. Phenotypes associated with three mutations (C1564S, L1649R and R1677Q) are distinct with the effect of C1564S being more severe than L1649R or R1677Q.

In this manuscript we address the prevalence of these mutations, in the US among other mutations responsible for adult type AS and we describe a cost effective and rapid molecular test targeted to these 3 mutations.

\section{Methods}

Adult-type AS was defined as median age of ESRD greater than 30 years in males. Cases were identified from the Utah Alport Study. The median age of ESRD in affected males in kindreds with a known COL4A5 mutation was calculated by Kaplan-Meier survival analysis (SPSS 16.0 for Mac). For two mutations, no males had reached ESRD. In these kindreds the median age of ESRD was expressed as greater than the age of the oldest living affected male. Gene-carrying males were stratified by mutation independently of whether they came from one family or from several families with the same mutation.

All gene-carriers known by June 2009 were tabulated and the proportions attributable to each mutation were calculated. Males were designated as affected (and therefore gene-carriers) if a mutation had been shown in the individual by genetic analysis using any of several methods $[1,5,6,8]$, or if a mutation had been shown in the kindred and the individual was on a line of descent for X-linked inheritance and had hematuria or renal failure. Females were designated as gene-carriers if a mutation had been shown in the individual by genetic analysis or if a mutation had been shown in the kindred and the individual was on the line of descent for X-linked inheritance and had hematuria, renal failure or was an obligate carrier.

For the molecular assay, DNA, obtained from approved IRB protocols and described previously $[5,6]$, was used for validation. Positive samples comprised both males and females. Nine had the C1564S mutation, 12 the R1677Q mutation and 13 the L1649R mutation. Samples with mutations in other COL4A5 exons and one non-affected male sample were used as confirmed negatives for the targeted mutations. Twenty of these were tested for C1564S and R1677Q and 17 were tested for L1649R.
Exons 49 (C1564S), 50 (L1649R) and 51 (R1677Q) were amplified by PCR in a LightCycler instrument (Roche Applied Science) using $0.5 \mu \mathrm{M}$ of primers and $0.2 \mu \mathrm{M}$ of probes shown in Table $1,3 \mathrm{mM} \mathrm{MgCl} 21 \times$ LightCycler DNA Master HybProbe (Roche Applied Science), UNG (0.1 unit of AmpErase Uracil N-glycosylase). For each mutation, probes comprised an anchor probe labeled in 3 ' with FITC and a reference probe that matches the non mutated sequence, labeled in $5^{\prime}$ with either LC705 (C1564S and L1649R) or LC640 (R1677Q) and blocked in 3' with a C3 blocker (Idaho Technology, Salt Lake City, Utah). Exons 49 and 51 were multiplexed while exon 50 was amplified individually with the following protocol: After pre-warming the instrument at $94^{\circ} \mathrm{C}$ for $10 \mathrm{~min}$. and cooling to $30^{\circ} \mathrm{C}$ for $1 \mathrm{~min}$., one UNG decontamination step was performed for $3 \mathrm{sec}$. at $50^{\circ} \mathrm{C}$ followed by UNG enzyme inactivation at $95^{\circ} \mathrm{C}$ for $5 \mathrm{~min}$. Amplification was for 60 cycles of $95^{\circ} \mathrm{C}$ for $0 \mathrm{sec}, 60^{\circ} \mathrm{C}$ for $10 \mathrm{sec}$ and $75^{\circ} \mathrm{C}$ for $15 \mathrm{sec}$. Ramp rate $\left({ }^{\circ} \mathrm{C} / \mathrm{sec}\right)$ between the steps were respectively 20, 20 and 2 . After amplification, the PCR product was melted as follow; $94^{\circ} \mathrm{C}$ for 30 seconds followed by cooling and holding at $45^{\circ} \mathrm{C}$ for 2 minutes. Temperature was then increased to $85^{\circ} \mathrm{C}$ at a rate of $0.1{ }^{\circ} \mathrm{C} / \mathrm{sec}$ while fluorescence was recorded in both the F2 (LC640) and the F3 (LC705) channels of the instrument in presence of the color compensation file. Negative derivative of melting curves were calculated using the LCDA 3.5 software and $T_{\mathrm{m}}$ of the probes was determined.

\section{Results and Discussion \\ Mutations at 3 loci account for the majority of all cases of adult-type AS in the US}

Mutations in Col4A5 were determined in several hundred adult type XLAS known or inferred gene -carriers (Table 2 ). Twenty two mutations were determined among which 9 were previously reported but not analysed for phenotype. L1649R mutation is found in $48.6 \%$ of all gene-car-

Table I: primers and probes sequences for each mutation

\begin{tabular}{ll}
\hline CI564S & \\
$\begin{array}{l}\text { Forward primer: } \\
\text { Reverse primer: }\end{array}$ & 5' gaaggcttccaatgaagcag \\
$\begin{array}{l}\text { Anchor probe: } \\
\text { Reference probe: }\end{array}$ & 5' ctgactgtgaactgcgatcaccacagctggagctt-FITC \\
& 5'LC705-acatactgcaCatctggtaaagg-C3 block \\
\hline LI649R & \\
$\begin{array}{l}\text { Forward primer: } \\
\text { Reverse primer: }\end{array}$ & 5' tttcgttcagctcccttc \\
Anchor probe: & 5' ggtaagcactttacctgaacatgtctactatgccaactcctaca-FITC \\
Reference probe: & 5'LC705-cttttggcTggcaactgt-C3 block \\
\hline $\begin{array}{l}\text { RI677Q } \\
\text { Forward primer: }\end{array}$ & 5' ccagaaaatgtggatctgattg \\
$\begin{array}{l}\text { Reverse primer: } \\
\text { Anchor probe: }\end{array}$ & 5' ttggggacaatgagacactg \\
Reference probe: & 5' cacaaaggaattcttcaaaatgttatgtcctcttcat-FITC \\
\end{tabular}


Table 2: Median age of ESRD in affected males and numbers of known gene-carriers in adult type Alport syndrome

\begin{tabular}{|c|c|c|c|c|c|}
\hline $\begin{array}{c}\text { COL4A5 mutation } \\
\text { [ref of previously published mutation] }\end{array}$ & ESRD age & Male & Female & Total & $\%$ of total \\
\hline leul649arg [6] & 39 & 150 & 222 & 372 & 48.6 \\
\hline cys I564Ser [I] & 32 & 52 & 81 & 133 & 17.4 \\
\hline $\arg \mid 677 g \ln [5]$ & 50 & 19 & 38 & 57 & 7.5 \\
\hline glyl170ser & 38 & 13 & 11 & 24 & 3.1 \\
\hline c.2476delC & 44 & 11 & 12 & 23 & 3.0 \\
\hline gln 1234ter & 42 & 7 & 16 & 23 & 3.0 \\
\hline c. $1424-20 \mathrm{~T}>\mathrm{A}$ & 32 & 7 & 12 & 19 & 2.5 \\
\hline cys I564arg & 33 & 9 & 9 & 18 & 2.4 \\
\hline prol584 leu & 34.5 & 6 & 9 & 15 & 2.0 \\
\hline $\arg \mid 563 g \ln [2]$ & 34.5 & 5 & 8 & 13 & 1.7 \\
\hline gly 1030ser [10] & 38 & 9 & 3 & 12 & 1.6 \\
\hline c. $687+\mid \mathrm{G}>\mathrm{A}$ & 33 & 7 & 4 & 11 & 1.4 \\
\hline gly763glu & 42 & 5 & 3 & 8 & 1.0 \\
\hline gly548asp & 45 & 6 & 2 & 8 & 1.0 \\
\hline gly 1244asp [8] & 57 & 3 & 3 & 6 & 0.8 \\
\hline arg|677pro [8] & 37.5 & 2 & 2 & 4 & 0.5 \\
\hline gly295asp [8] & 49.5 & 3 & I & 4 & 0.5 \\
\hline gly719arg & $>38$ & 2 & 2 & 4 & 0.5 \\
\hline c. $3554-3 C>G[10]$ & 31 & 2 & 2 & 4 & 0.5 \\
\hline gly533glu & 32 & 1 & 2 & 3 & 0.4 \\
\hline c.4177delC & 35 & 2 & 0 & 2 & 0.3 \\
\hline gly325gln & $>41$ & 1 & 1 & 2 & 0.3 \\
\hline Total & & 322 & 443 & 765 & 100.0 \\
\hline
\end{tabular}

riers for adult-type AS, the C1564S mutation in $17.4 \%$ and R1677Q mutation in 7.5\%. When C1564R and $\mathrm{R} 1677 \mathrm{P}$ are included, missense mutations at positions 1564, 1649, and 1677 account for $76.4 \%$ of all mutant genes for adult-type AS in our kindreds.
Information in the Utah Alport Study has been collected since 1949 when Tyler and Perkoff began to investigate nephritis in four related men who were subsequently shown to carry the C1564S mutation [9]. There is obvious potential for ascertainment bias favouring larger numbers in this kindred because the C1564S family was the first to 
be studied and there has been more time to ascertain members than in other kindreds. We cannot completely exclude ascertainment bias, but during the 60 years of the Utah Alport Study cases have accumulated from across the whole of the United States and for most of this time our center was the only one collecting cases on a systematic basis. There has been ample opportunity to discover a large proportion of the kindreds with AS in the US. As an example, 22 apparently unrelated families with the L1649R mutation have come to light and this is now the most prevalent mutation. Twelve of these families were shown by haplotype analysis to have arisen from a common ancestor [6]. Although it is possible that other large kindreds exist but have not come to light over 60 years of data collection, this seems unlikely. It is also possible that there are as yet unrecognized branches of known families.

Ascertainment bias within kindreds is shown in the ratio of females to males identified. For an X-linked condition at equilibrium there will be twice as many female as male gene-carriers. The overall F:M proportion in our study was 1.39. It was higher in the 3 largest kindreds at $1.48,1.56$, and 2.0 respectively, but only 0.77 in the families with 4 or fewer identified gene-carriers. Gender-specific ascertainment bias is expected in an X-linked condition because males are more severely affected and thus come to notice.

Despite inaccuracies introduced by ascertainment bias, our data are the only systematic compilation of adult-type AS mutations in the US. We believe that they provide a reasonable approximation of the relative frequencies of different adult-type mutations.

\section{Molecular assay for the detection of L I 649R, R I 677Q and CI564S mutations}

We have developed a molecular assay using fluorescently labeled hybridization probes that detect the three main US mutations. The C1638Y mutation recently described in New Zealand [7] and other rare mutation (Table 2) are not included in this test. The assay uses melting curve analysis of three allele specific hybridization probes. Melting analysis of the C1564S probe (Figure 1) shows one single melting curve in the four positive males with a melting temperature $\left(T_{\mathrm{m}}\right)$ of $56.7^{\circ} \mathrm{C}$, two melting curves in the five heterozygotes females $\left(T_{\mathrm{m}} \mathrm{s}=56.7^{\circ} \mathrm{C}\right.$ and $65.8^{\circ} \mathrm{C}$ ), and a single melting curve in 22 samples negative for the mutation $\left(T_{\mathrm{m}}=65.8^{\circ} \mathrm{C}\right)$. The curves correspond to the dissociation of the probe with the mutant and normal allele, respectively. Genotyping of this locus was $100 \%$ accurate.

The L1649R probe was tested on nine positive males, four positive females and 17 samples with other mutations in COL4A5. Melting analysis of the probe revealed a single peak $\left(T_{\mathrm{m}}=57.4^{\circ} \mathrm{C}\right)$ in positive males, two peaks in heterozygous females $\left(T_{\mathrm{m}} \mathrm{s}=57.4^{\circ} \mathrm{C}\right.$ and $\left.65.3^{\circ} \mathrm{C}\right)$ and a single peak in samples without the mutation $\left(T_{\mathrm{m}} \mathrm{s}=65.3^{\circ} \mathrm{C}\right)$. Accuracy was $100 \%$.

The R1677Q mutation was analyzed in six positive males, five carrier females and a positive sex-undetermined sample. Twenty-two samples without the mutation were also tested. Two of these had mutations in the same codon as R1677Q (R1677X [10] and R1677P [8]) and are associated with juvenile XLAS (unpublished). The melting peak corresponding to the presence of the mutation is $57.4^{\circ} \mathrm{C}$ while the melting peak of the normal allele is $65.1^{\circ} \mathrm{C}$. The R1677X mutation was detected by a melting curve at $60.0^{\circ} \mathrm{C}$ and the R1677P mutation at $56.3^{\circ} \mathrm{C}$, both distinguishable from the targeted mutation. All positives and negative samples were correctly identified by the assay.

Precision of the assay was performed by analyzing a sample of each genotype in triplicate in one experiment (within run variation) and in five independent experiments (between run variation). Values of $T_{\mathrm{m}} \mathrm{s}$ and difference of $T_{\mathrm{m}} \mathrm{s}$ between the curves (in heterozygous females) were used to determine the precision of the assays. Two standard deviations were calculated from the averages and did not exceed $0.5^{\circ} \mathrm{C}$ for $T_{\mathrm{m}} \mathrm{s}$ and $0.25^{\circ} \mathrm{C}$ for delta $T_{\mathrm{m}} \mathrm{s}$.

The assay identified all the targeted mutations present in the positive samples and none in negative samples; it has accuracy, analytical sensitivity and specificity above $99 \%$. Because the mutations are familial and are carried on single haplotypes, it is unlikely that unreported polymorphisms under the PCR primers or the probes will affect the analytical sensitivity or specificity of the assay.

Males with one COL4A5 mutation are predicted to be affected with AS while women with one mutation are carriers and may or may not develop symptoms. The C1564S, which likely disrupts the collagen IV network by disabling formation of a disulfide bond is the most severe of the three. Fifty percent of males positive for C1564S are expected to have ESRD by age 32 and hearing loss by age 25. The mutation L1649R substitutes a neutral amino acid for a charged amino acid in the NC1 domain. ESRD is expected for $50 \%$ of L1649R positive males by age 38 and hearing loss by age 45 [6]. Typical age of ESRD in males with the R1677Q mutation is 38 years [5].

Other mutations associated with adult type AS, Table 2 and $[2,7]$ or with juvenile type AS will not be detected. Clinical sensitivity for adult type XLAS in U.S. Caucasian population is estimated to be around $75 \%$ and clinical specificity is $99 \%$. Other testing approaches such as sequencing and detection of duplications and deletions in 

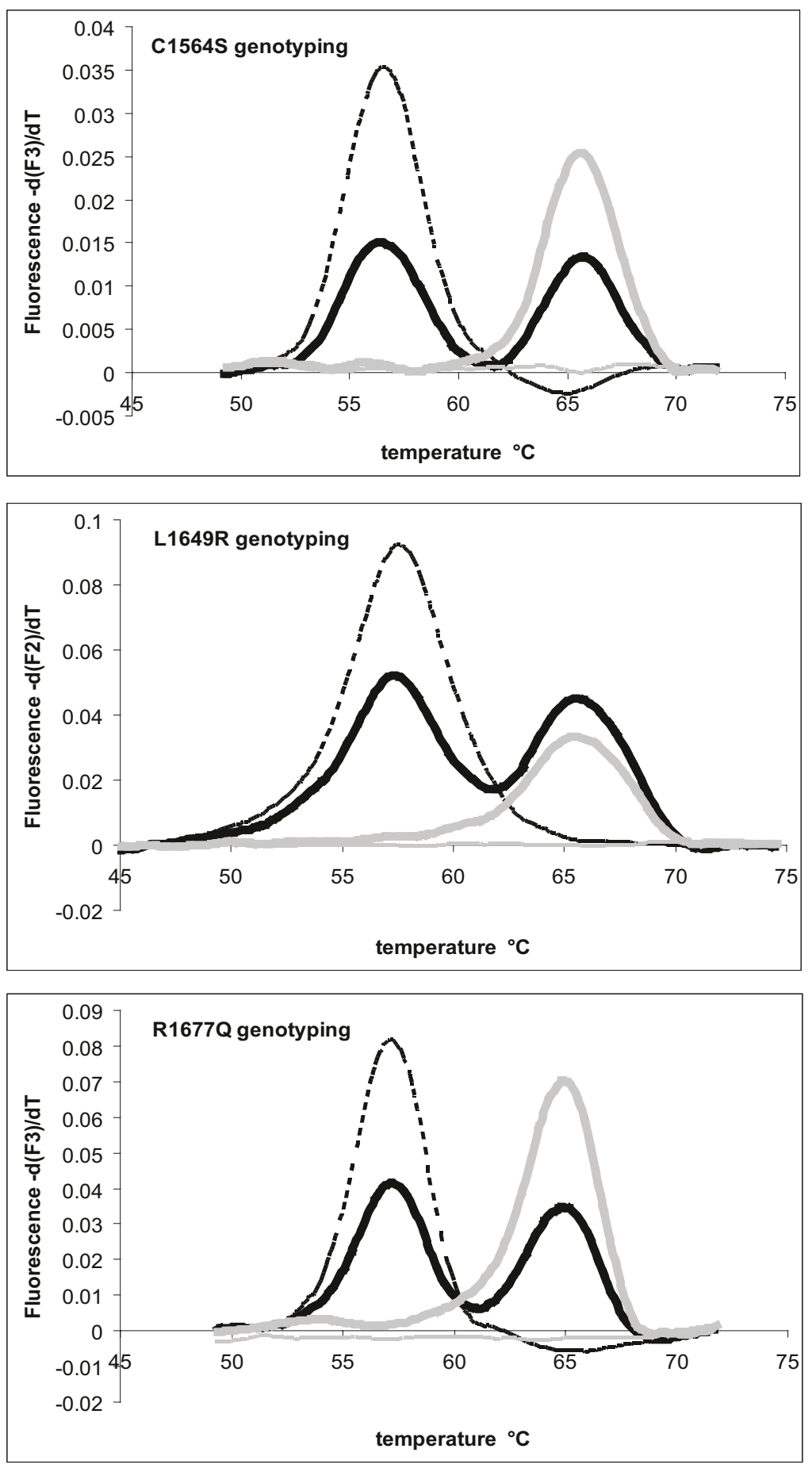

\section{Figure I}

Genotyping of CI564S, LI 649R, and RI677Q by melting curve analysis. Each graph analyzes one of the mutations with DNA from a positive male (dotted line), a female carrier (black line), a normal individual (grey line) and a no template control (thin grey line). Fluorescence on the $Y$ axis is the negative derivative of fluorescence in function of temperature. Positions of the peaks indicate the dissociation of the probes with a given allele. As probes are homologous to the normal allele, lower $T_{\mathrm{m}} \mathrm{s}$ correspond to the mutant alleles and higher $T_{\mathrm{m}} \mathrm{s}$ to the normal allele. 
COL4A5, COL4A3 and COL4A4 need to be used to detect all genetic mutations implicated in AS.

\section{Conclusion}

This assay is designed to detect mutations responsible for the majority of adult type AS in the US. It is recommended for diagnostic, pre-symptomatic, or carrier testing of individuals from families known to carry one of the COL4A5 mutations tested: C1564S, L1649R or R1677Q. Adult type AS is likely substantially under-diagnosed because the $\mathrm{X}$ linked pattern of inheritance frequently conceals the familial nature of the disease and because hearing loss is subtle in many cases. This assay may help elucidate otherwise unexplained hematuria or chronic kidney disease in men, and unexplained hematuria in woman with a family history of chronic kidney disease.

\section{Competing interests}

The authors declare that they have no competing interests.

\section{Authors' contributions}

GPK designed the assay, acquired and analyzed data. KS performed experiments. FG sequenced the samples with the mutations. CM was involved in test interpretation and utility, JD collected pedigree information and MG provided genotyped samples and performed the demographic analyses. EL directed the project. All authors read and approved the final manuscript.

\section{Acknowledgements}

This work was supported by the ARUP Institute for Clinical and Experimental Pathology ${ }^{\circledR}$, ARUP Laboratories, Salt lake City, Utah, USA. Original sample collection and genotyping received funding from the Curtis L. Atkin Foundation.

\section{References}

I. Barker DF, Hostikka SL, Zhou J, Chow LT, Oliphant AR, Gerken SC Gregory MC, Skolnick MH, Atkin CL, Tryggvason K: Identification of mutations in the COL4A5 collagen gene in Alport syndrome. Science 1990, 248(4960): 1224- I 227.

2. Gross O, Netzer KO, Lambrecht R, Seibold S, Weber M: Meta-analysis of genotype-phenotype correlation in X-linked Alport syndrome: impact on clinical counselling. Nephrol Dial Transplant 2002, I7(7): | 2 |8-1227.

3. Jais JP, Knebelmann B, Giatras I, De Marchi M, Rizzoni G, Renieri A, Weber M, Gross O, Netzer KO, Flinter F, et al.: X-linked Alport syndrome: natural history and genotype-phenotype correlations in girls and women belonging to 195 families: a "European Community Alport Syndrome Concerted Action" study. J Am Soc Nephrol 2003, I4(I 0):2603-26I0.

4. Jais JP, Knebelmann B, Giatras I, De Marchi M, Rizzoni G, Renieri A, Weber M, Gross O, Netzer KO, Flinter F, et al: X-linked Alport syndrome: natural history in 195 families and genotype- phenotype correlations in males. I Am Soc Nephrol 2000 I I(4):649-657.

5. Barker DF, Denison JC, Atkin CL, Gregory MC: Common ancestry of three Ashkenazi-American families with Alport syndrome and COL4A5 R I677Q. Hum Genet 1997, 99(5):68I-684

6. Barker DF, Pruchno CJ, Jiang X, Atkin CL, Stone EM, Denison JC, Fain PR, Gregory MC: A mutation causing Alport syndrome with tardive hearing loss is common in the western United States. Am J Hum Genet 1996, 58(6): I I57-I I 65.
7. Wilson JC, Yoon HS, Walker RJ, Eccles MR: A novel Cys I 638Tyr NCI domain substitution in alpha5(IV) collagen causes Alport syndrome with late onset renal failure without hearing loss or eye abnormalities. Nephrol Dial Transplant 2007, 22(5): I338-1346.

8. Barker DF, Denison JC, Atkin CL, Gregory MC: Efficient detection of Alport syndrome COL4A5 mutations with multiplex genomic PCR-SSCP. Am J Med Genet 200I, 98(2): I 48- I60.

9. Perkoff GT, Stephens FE, Dolowitz DA, Tyler FH: A clinical study of hereditary interstitial pyelonephritis. AMA Arch Intern Med 1951, 88(2): 191-200.

10. Martin P, Heiskari N, Zhou J, Leinonen A, Tumelius T, Hertz JM, Barker D, Gregory M, Atkin C, Styrkarsdottir U, et al.: High mutation detection rate in the COL4A5 collagen gene in suspected Alport syndrome using PCR and direct DNA sequencing. J Am Soc Nephrol 1998, 9(I 2):229I-230I.

\section{Pre-publication history}

The pre-publication history for this paper can be accessed here:

http://www.biomedcentral.com/1471-2369/10/38/pre pub
Publish with Bio Med Central and every scientist can read your work free of charge

"BioMed Central will be the most significant development for disseminating the results of biomedical research in our lifetime. "

Sir Paul Nurse, Cancer Research UK

Your research papers will be:

- available free of charge to the entire biomedical community

- peer reviewed and published immediately upon acceptance

- cited in PubMed and archived on PubMed Central

- yours - you keep the copyright
BioMedcentral 